\title{
Association of registered nurse and nursing support staffing with inpatient hospital mortality
}

\author{
Jack Needleman (D) , ${ }^{1}$ Jianfang Liu, ${ }^{2}$ Jinjing Shang, ${ }^{2}$ Elaine L Larson, ${ }^{2,3}$ \\ Patricia W Stone ${ }^{4}$
}

\begin{abstract}
- Additional material is published online only. To view please visit the journal online (http://dx.doi.org/10.1136/ bmjas-2018-009219).

${ }^{1}$ Department of Health Policy and Management, Fielding School of Public Health, UCLA, Los Angeles, California, USA ${ }^{2}$ School of Nursing, Columbia University, New York, NY, United States

${ }^{3}$ Columbia University Mailman School of Public Health, New York City, New York, USA ${ }^{4}$ Center for Health Policy, School of Nursing, Columbia University, New York, NY, United States
\end{abstract}

\section{Correspondence to}

Dr Jack Needleman, Department of Health Policy and Management, Fielding School of Public Health, UCLA, Los Angeles, CA 90095, USA; needlema@ucla.edu

Received 13 December 2018

Revised 8 July 2019

Accepted 9 July 2019

Published Online First

7 August 2019

\section{Sinked}

- http://dx.doi.org/10.1136/ bmjqs-2019-009732

\section{Check for updates}

(c) Author(s) (or their employer(s)) 2020. No commercial re-use. See rights and permissions. Published by BMJ.

To cite: Needleman J, Liu J, Shang J, et al. BMJ Qual Saf 2020;29:10-18.

\begin{abstract}
Background The association of nursing staffing with patient outcomes has primarily been studied by comparing high to low staffed hospitals, raising concern other factors may account for observed differences. We examine the association of inpatient mortality with patients' cumulative exposure to shifts with low registered nurse (RN) staffing, low nursing support staffing and high patient turnover.
\end{abstract}

Methods Cumulative counts of exposure to shifts with low staffing and high patient turnover were used as time-varying covariates in survival analysis of data from a three-campus US academic medical centre for 20072012. Staffing below $75 \%$ of annual median unit staffing for each staff category and shift type was characterised as low. High patient turnover per day was defined as admissions, discharges and transfers 1 SD above unit annual daily averages.

Results Models included cumulative counts of patient exposure to shifts with low RN staffing, low nursing support staffing, both concurrently and high patient turnover. The HR for exposure to shifts with low RN staffing only was $1.027(95 \% \mathrm{Cl} 1.002$ to 1.053 , $\mathrm{p}<0.001)$, low nursing support only, 1.030 (95\% Cl 1.017 to $1.042, \mathrm{p}<0.001)$ and shifts with both low, $1.025(95 \% \mathrm{Cl} 1.008$ to $1.043, p=0.035)$. For a model examining cumulative exposure over the second to fifth days of an admission, the HR for exposure to shifts with low RN staffing only was 1.048 (95\% Cl 0.998 to $1.100, p=0.061$ ), low nursing support only, 1.032 $(95 \% \mathrm{Cl} 1.008$ to $1.057, \mathrm{p}<0.01)$ and for shifts with both low, $1.136(95 \% \mathrm{Cl} 1.089$ to $1.185, \mathrm{p}<0.001)$. No relationship was observed for high patient turnover and mortality.

Conclusion Low RN and nursing support staffing were associated with increased mortality. The results should encourage hospital leadership to assure both adequate $\mathrm{RN}$ and nursing support staffing.

Assuring adequate nurse staffing in hospitals remains a contentious issue in healthcare management and national and local policy. While a number of studies conducted in the USA and internationally have found an association between inpatient nurse staffing and mortality, other adverse patient outcomes and longer lengths of stay, ${ }^{1-13}$ most investigators compare high and low staffed hospitals and use staffing averaged over months or a full year, or based on one-time reports by nurses of staffing on their last shift. While these studies suggest that low staffing increases adverse events and length of stay, they do not fully address the causal association of staffing and outcomes, leaving room to argue that other related factors rather than low staffing itself are the actual causal pathways for the associations observed of staffing and outcomes. More important, the high-low comparisons do not specifically capture or define the level of staffing that makes it difficult for nurses to deliver safe and reliable work nor do they directly address the organisation of nursing care and nursing teams in hospitals.

Additionally, the published research assessing staffing mix, the proportion of nursing and nursing support staff (licensed practical nurses (LPNs) and nurse's aides) who are registered nurses (RNs) has been interpreted as reflecting efforts to substitute non-RNs to perform work that is the domain of RNs, including assessment and monitoring, patient surveillance, delivery of complex therapies, patient education and psychosocial support and preparation for self-care and discharge, among other activities. $^{3714-17}$ These studies of staff mix do not address the question of whether, when support staffing is low, RNs are asked to carry more of the work of the support staff, to the detriment of patient care.

In this study, we examine the association of RN and nursing support staffing on inpatient mortality using a data set that allows us to measure staffing for each unit and each shift, to identify shifts in which staffing is substantially lower than is typical and to measure for each patient the impact on risk of mortality of 
exposure to low staffed shifts. In an important extension of past work, we examined exposure to shifts with low RN staffing, low nursing support staffing and shifts for which RN and nursing support staffing were both low.

\section{METHODS}

To assess the association between mortality and low RN and nursing support staffing, we conducted a survival analysis using Cox proportional hazards regression models with time from hospital admission as the time scale and in-hospital death as the outcome.

\section{Study oversight}

This study (R01NR010822) was designed by the research team and approved by the university and medical centre institutional review boards. Members of the research team jointly provided direction and oversight of the analysis, writing and submission of the manuscript for publication.

\section{Data and sample}

This is a secondary data analysis. The study was conducted in a large urban US academic health system with three hospitals (two tertiary hospitals and one community hospital), with more than 2000 beds and over 100000 patient discharges per year.

Using information from the hospital payroll system, we constructed for each unit and each 12 hours shift (day: 07:00 hours to 19:00 hours and night: 19:00 hours to $07: 00$ hours) the number of hours attributed to the unit for each staffing category (RN, LPN, nurse's aide). LPN and nurse's aides were combined into the category of nursing support staff. This decision was made after a review of staffing patterns found that LPNs were a small share of the nursing staff (less than $10 \%$ of the combined LPN-nurse's aide hours) and that they were used in a limited manner in these hospitals. For each unit and shift, we estimated the census and hours of nursing per patient for the unitshift. We excluded from our sample 6076 unit-shifts (from a total of 140448 ) with RN staffing levels so low that nursing administrators in the system judged likely due to data error rather than actual staffing. Unit-shifts with patient-to-RN ratios higher than 4 for intensive care units (ICUs), 8 for medical and medical/surgical units and 6 for step-down units were excluded on this basis. Patients assigned to any of these unit-shifts were excluded from the sample. Using the system's clinical data warehouse, we identified the unit on which each patient was hospitalised on each day of their admission. Data for unit assignment were not available for a substantial number of patients for their first day of admission, and we excluded all data on first day staffing from analysis.

The patient sample was restricted to adult, nonsurgical and non-psychiatric patients, without community acquired infections, with lengths of stay of three

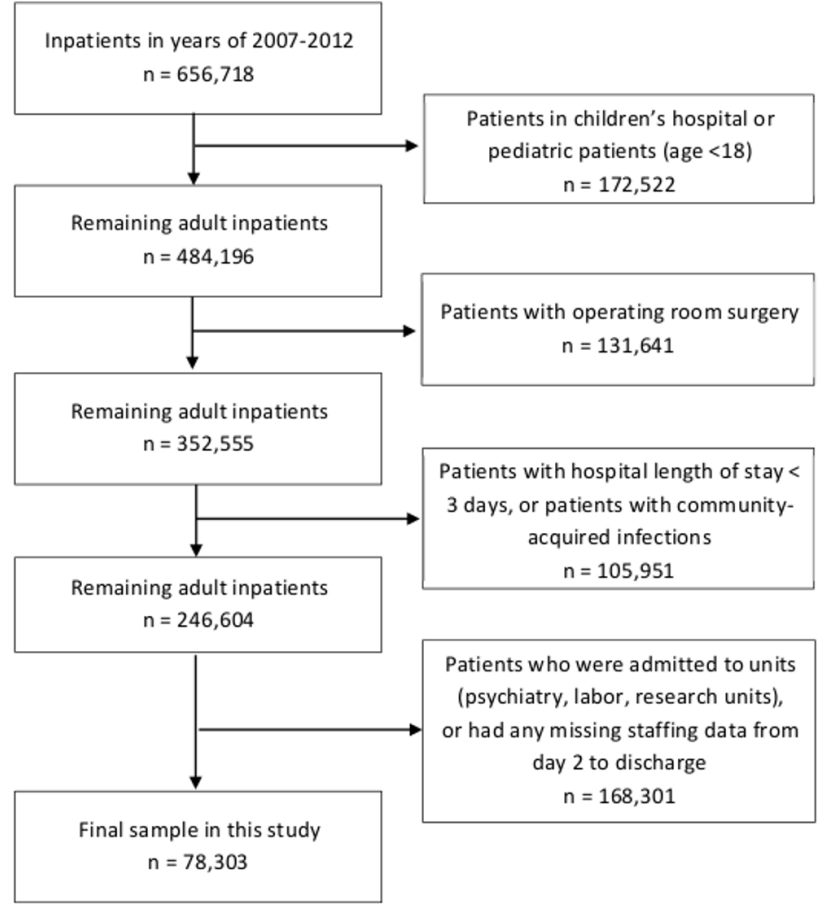

Figure 1 Patient sample included in the analysis.

or more days, and admissions on unit-shifts for which staffing data were available (see figure 1). Our final sample was 78303 adult medical admissions on 133 742 unit-shifts.

\section{MEASURES}

\section{In-patient mortality}

Death at hospital discharge was coded from the patient discharge abstract.

\section{Unit-shift measures of low registered nurse and nursing support staffing}

The academic medical centre whose data we use does not maintain a historic record of target staffing for each unit shift, a measure used in a prior study to measure low staffing as a substantial gap between target and actual staffing. ${ }^{9}$ In this study, therefore, we use a measure of staffing substantially below typical for the unit and shift as a measure of low staffing. To assess whether unit-shift staffing was substantially lower than typical, we estimated the median hours per patient for RNs and nursing support staff for each unit on its day and night shifts and used this as a measure of typical staffing. We characterised a shift as low staffed for RNs or nursing support staff if the hours per patient for the shift was less than $75 \%$ of the median for each category of staff.

We considered as cutoffs for low staffing 65\%, $75 \%, 80 \%$ and $85 \%$ of the median staffing. The lower cutoffs increase the difference from median staffing considered low staffing and also reduce the number of shifts with low staffing, making the estimates less precise. This is a specific issue for shifts with both 
RN and nursing supporting (NS) staffing low, and particularly for analysis at the $65 \%$ threshold. As the threshold is set closer to the median, more shifts are included in the count of low staffing, but the shortfall of low staffing is smaller. To put this in context, at a threshold for low staffing of $80 \%$ of the median, $12 \%$ of the day shifts and $15 \%$ of the nightshifts met the criteria for low RN staffing. At a75\% threshold, these are reduced to $10 \%$ and $9 \%$, respectively. A cut-off at $75 \%$ of the median, used in our analysis, represents an appropriate tradeoff between a deeper measure of low staffing and adequate numbers of shifts with low staffing to analyse.

Three zero-one low staffed variables was constructed for each unit-shift, one set to one when only RN staffing was low on the shift, the second set to one when only nurse support staffing was low, and the third set to one when both RN and nursing support staffing was low. For each patient, a cumulative count of exposure to shifts with only low RN staffing, only low nursing support staffing and both low RN and nursing support staffing were included in a survival analysis as time varying covariates.

As an alternative to constructing three mutually exclusive measures of exposure, we considered constructing an interaction term for shifts with both low RN staffing and low nursing support staffing. We would then use in the analysis variables the cumulated counts of shifts with any low RN staffing, any low nursing support staffing and a cumulative count of the interaction, that is, counts of when both staffing categories were low on a shift. This would be the standard approach to assessing an interaction in a linear model. We were concerned, however, that because we are using a hazard model in which cumulative counts are time varying covariates, the standard approach to implementing and interpreting an interaction might not be appropriate. To accommodate this concern, we opted for the construction of the three mutually exclusive measures of cumulative exposure.

\section{Patient turnover}

Because demands on nursing staff increase as admissions, transfers or discharges increase, we constructed a measure of patient turnover for each shift equal to the sum of unit admissions, transfers and discharges, divided by start-of-shift census. This ratio was multiplied by 100 and divided by 2, so complete patient turnover would equal $100 \%$. A shift was defined as high-turnover if turnover was greater than or equal to the mean plus $1 \mathrm{SD}$ of the day-shift turnover for that unit, and a dummy variable for high-turnover was merged into the patient-unit-shift record.

\section{Patient-level measures}

Patient-level measures obtained from discharge summary and used to adjust for the risk of mortality included age, gender, and Charlson comorbidity score, a measure incorporating weighted counts of comorbidities. ${ }^{18} 19$

\section{Time trends}

To allow for seasonal variation in mortality, categorical variables for month were included in the model. To control for time trends in mortality, categorical variables for year were included.

\section{Statistical analysis}

Characteristics of patients, units and shifts were summarised with means and SD of continuously scaled variables and counts and percentages for categorical variables. For each unit, we calculated the proportion of shifts with low staffing and examined the distribution of these low staffed shifts across patients. We calculated the mean and SD of patient turnover and proportion of shifts with high-turnover.

Associations between mortality, nurse staffing and other variables were analysed using Cox proportional hazards regression models. Patient-level variables were included in the models to account for differences in mortality risk. The Cox models included cumulative counts of exposure to low-staffed and high-turnover shifts as time varying covariates.

To match a previous study using similar methods, ${ }^{9}$ we constructed models that only included cumulative counts of shifts with low RN staffing or high patient turnover. We then constructed additional models that include cumulative counts of shifts with low RN staffing, low nursing support staffing, shifts with both low RN and low nursing support staffing and high turnover. Results are reported for the cumulative number of shifts with staffing $75 \%$ of or lower than the median.

There are three issues with using cumulative counts of exposure to shifts with low staffing in these analyses. First, to the extent that exposure early in an admission leads to an adverse event that extends the admission, and thus increases exposure to additional shifts with low staffing, exposure to shifts with low staffing may be endogenous. Second, to the extent mortality is associated with longer lengths of stay, there is a potential for reverse causality, with increased mortality risk associated with higher exposure to shifts with low staffing. Third, patients are likely to have higher nursing acuity earlier in an admission, making them more sensitive during this period to low staffing. In light of these concerns, we also modelled cumulative exposure to low staffed and high patient turnover shifts for the first days of an admission only, specifically the second to fifth day of each admission. The survival model uses this constrained count but models the hazard of mortality over the full admission. While the counts of cumulative exposure will be lower in this shorter period, we anticipate the association of exposure to low staffing or higher turnover to be more pronounced for this period. 
Table 1 Nurse staffing and proportion of understaffed shifts, by staff category, unit type and shift

\begin{tabular}{|c|c|c|c|c|c|}
\hline Variable & ICUs & Medical units & Med/Surg units & Step-down units & All \\
\hline \multicolumn{6}{|l|}{ Day shift } \\
\hline No. of shifts & 27331 & 18793 & 10016 & 10731 & 66871 \\
\hline \multicolumn{6}{|l|}{$\mathrm{RN}$} \\
\hline RN nursing hours/patients (mean (SD)) & $11.5(6.6)$ & $3.4(2.2)$ & $2.6(2.1)$ & $3.8(1.6)$ & $6.7(6.0)$ \\
\hline $75 \%$ of RN staffing median & 7.8 & 2.1 & 1.8 & 2.8 & 4.5 \\
\hline Understaffed shifts (\%) & 13 & 8 & 6 & 10 & 10 \\
\hline \multicolumn{6}{|l|}{ NS } \\
\hline NS nursing hours/patients (mean (SD)) & $2.3(2.3)$ & $1.8(1.0)$ & $2.0(1.3)$ & $1.5(0.8)$ & $2.0(1.7)$ \\
\hline $75 \%$ of NS staffing median & 1.4 & 1.3 & 1.4 & 1.1 & 1.3 \\
\hline Understaffed shifts (\%) & 28 & 15 & 18 & 23 & 22 \\
\hline \multicolumn{6}{|l|}{ Night shift } \\
\hline No. of shifts & 27331 & 18793 & 10016 & 10731 & 66871 \\
\hline \multicolumn{6}{|l|}{ RN } \\
\hline RN nursing hours/patients (mean (SD)) & $11.1(6.6)$ & $3.2(2.1)$ & $2.4(2.0)$ & $3.7(1.5)$ & $6.4(5.9)$ \\
\hline $75 \%$ of RN staffing median & 7.4 & 2.0 & 1.6 & 2.7 & 4.3 \\
\hline Understaffed shifts (\%) & 13 & 6 & 3 & 8 & 9 \\
\hline \multicolumn{6}{|l|}{ NS } \\
\hline NS nursing hours/patients (mean (SD)) & $1.9(2.1)$ & $1.5(1.0)$ & $1.6(1.2)$ & $1.3(0.7)$ & $1.6(1.5)$ \\
\hline $75 \%$ of NS staffing median & 1.2 & 1.0 & 1.2 & 1.0 & 1.1 \\
\hline Understaffed shifts (\%) & 28 & 19 & 17 & 22 & 23 \\
\hline
\end{tabular}

Understaffing defined as the staffing is lower than $75 \%$ of the shift median for each unit type and each type of nursing staff.

ICU, intensive care unit; NS, nursing supporting staff; RN, registered nurses.

Regression models including these variables were used to estimate HRs and 95\% CI. HRs were tested for significance using two-sided Wald tests. Schoenfeld residuals were examined to assess whether the proportionality assumption of the Cox model was met. Plots were consistent with proportionality. All statistical analyses were conducted using SAS, V.9.3.

\section{RESULTS}

\section{Unit and unit staffing characteristics}

Over the study period, in our analytic sample, there were 133742 staffed unit-shifts; 43\% were in medical or medical-surgical units, $41 \%$ in critical care and $16 \%$ in step-down units (table 1). Patient turnover across these shifts averaged $33 \%$ but was highly variable (SD $16 \%)$. Eight per cent of shifts were categorised as highturnover (table 2).

Ten per cent of day shifts and $9 \%$ of night shifts had RN staffing lower than $75 \%$ of the median staffing, with ICUs more likely to have low staffing (table 1). Twenty-two per cent of day shifts and 23\% of night shifts had nursing support staffing lower than $75 \%$ of the median staffing, again with ICUs more likely to have low staffing. On day shifts, $44 \%$ of shifts with low RN staffing had low nursing support staffing; $19 \%$ of the shifts without low RN staffing had low nursing support staffing. Twenty-one per cent of shifts with low nursing support staffing had low RN staffing. On night shifts, these percentages were 43\%, 21\% and $17 \%$, respectively (analysis not shown).

\section{Patient characteristics}

Forty-seven per cent of patients were male (table 2). The mean age was 62 years, with a range from 18 to 112. The average Charlson comorbidity score was 2.4 , with a range from 0 to 21 , demonstrating a wide range of comorbidity among this population but mostly at the low end of the range.

\section{Mortality}

Mortality in this sample was $3.9 \%$ (table 2). This mortality rate is reasonable for a hospitalised population in which surgical, paediatric, labour and delivery, psychiatric and rehabilitation patients are excluded. Mortality declined slightly over the 6-year period studied, from $4.2 \%$ in 2007 to $3.6 \%$ in 2012 . These year-to-year changes are accommodated in our modelling by including year as a fixed effect.

\section{Low staffing, high-turnover and mortality}

Table 3 presents the number of shifts experienced by patients during the study time period with either low staffing or high-turnover. Looking over the entire admission, $70 \%$ of patients experienced no shifts with low RN staffing and 36\% no shifts with low nursing support staffing. Eighty-nine per cent of patients experienced no shifts with both low $\mathrm{RN}$ and low nursing support staffing. Nearly $30 \%$ of patients had one or more shifts with only low RN staffing, $64 \%$ one or more shifts with only low nursing support staffing and $11 \%$ one or more shifts with both low RN and nursing 
Table 2 Patient, unit and nursing shift characteristics

\begin{tabular}{|c|c|}
\hline Variable & Value \\
\hline \multicolumn{2}{|l|}{ Patients } \\
\hline No. of admissions & 78303 \\
\hline Deaths-no. (\%) & $3043(3.9)$ \\
\hline \multicolumn{2}{|l|}{ Age-years } \\
\hline Mean (SD) & $62.0(19.0)$ \\
\hline Range & $18-112$ \\
\hline Male sex-no. (\%) & $37026(47.3)$ \\
\hline \multicolumn{2}{|l|}{ Charlson Index } \\
\hline Mean (SD) & $2.4(2.5)$ \\
\hline Range & $0-21$ \\
\hline \multicolumn{2}{|l|}{ Units } \\
\hline Intensive care unit—no. (\%) & $13(38)$ \\
\hline Medical—no. (\%) & $9(26)$ \\
\hline Medi-surg—no. (\%) & $6(18)$ \\
\hline Step-down care-no. (\%) & $6(18)$ \\
\hline \multicolumn{2}{|l|}{ Shifts } \\
\hline No. of patient days & 453429 \\
\hline \multicolumn{2}{|l|}{ All shifts } \\
\hline No. of shifts & 133742 \\
\hline No. shifts with low RN staffing-no. (\%) & $13134(9.8)$ \\
\hline No. shifts with low NS staffing一no.(\%) & $29999(22.4)$ \\
\hline No. shifts with low RN and NS staffing-no.(\%) & $5725(4.3)$ \\
\hline \multicolumn{2}{|l|}{ Patient turnover } \\
\hline \multicolumn{2}{|l|}{ Patient turnover per day } \\
\hline Mean & $0.33(0.16)$ \\
\hline Range & $0-1.00$ \\
\hline Per cent of shifts with high patient turnover & 8.0 \\
\hline
\end{tabular}

NS, nursing supporting staff; $R N$, registered nurses.

support staffing. The proportion of patients experiencing no low staffed shifts were higher when exposure was limited to the counts from the second to fifth days of an admission, with the increase varying from three to seven percentage points (table 3).

Forty-five per cent of patients experienced no higher turnover days, with 32\% experiencing one, 14\% experiencing two and $9 \%$ three or more. When counts from the second to fifth days of admission were considered, $56 \%$ experienced no high turnover days and $32 \%$ one high turnover day.

Four survival models are presented that include measures of patient variables, and the exposure to low RN staffing, low nursing support staff, both, and high turnover are presented in table 4 (full regression results are in online supplementary appendix 1). Paralleling prior studies, ${ }^{9}$ Model 1 presents results for the measure of the cumulative number of low RN staffed shifts experienced. Mortality risk increased with exposure to more low staffed RN shifts (HR per low staffed shift, 1.023 , 95\% CI 1.011 to 1.035$)$. When this exposure was restricted to the second to fifth days of admission (Model 2), the HR increased to 1.091 (95\% CI 1.059 to 1.125$)$.
In Model 3, using cumulative counts from staffing over the entire stay, the HRs on exposure to shifts with only low RN staffing, only low nursing support staffing, and both low RN and nursing support staffing were all greater than one and statistically significant, with similar estimated hazard ratios for each of the three staffing variables (low RN: 1.027, 95\% CI 1.002 to $1.053, \mathrm{p}=0.035$; low nursing support: $1.030,95 \%$ CI 1.017 to $1.042, \mathrm{p}<0.001$; both low $\mathrm{RN}$ and nursing support: $1.025,95 \%$ CI 1.008 to $1.043, \mathrm{p}=0.004$ ).

For the reasons discussed in the Methods section, we expect the estimated association of staffing and mortality to be larger in Model 4, which considers exposure only during the second to fifth days of admission. The estimated hazard for only low RN shifts increases to 1.048 . The $95 \%$ CI widens to include the null of one (0.998 to 1.100), reflecting the greater imprecision due to the smaller number of low $\mathrm{RN}$ shifts in the shorter period. Despite a $\mathrm{p}$ value of 0.061 , above the standard threshold of 0.05 , because the change is consistent with expectations, we view these results as consistent with an association. The estimate for exposure to only low nursing support shifts does not change very much between Models 3 and 4 (1.032, 95\% CI 1.008 to $1.057, p=0.01)$. The estimated hazard for exposure to shifts with both low RN and nursing support staffing increases substantially over the Model 3 estimate to 1.136 (95\% CI 1.089 to $1.185, \mathrm{p}<0.001)$, above the level associated with only low $\mathrm{RN}$ or nursing support staffing.

Exposure to high-turnover shifts was not significantly associated with increased mortality risk (HR per high-turnover shift: Model 1: 0.984, 95\% CI 0.955 to 1.013; Model 2: $0.970,95 \%$ CI 0.924 to 1.017 ; Model 3: 0.990, 95\% CI 0.962 to 1.020 ; Model 4: $0.976,95 \%$ CI 0.930 to 1.024 ).

\section{DISCUSSION}

Measuring low staffing as below $75 \%$ of the median for a unit, we found low RN staffing on 10\% of day shifts and $9 \%$ of night shifts, and low nursing support staffing from LPNs and nurse assistants on over 20\% of day and night shifts. Units also had higher than usual turnover, defined as turnover one SD above mean turnover, on $8 \%$ of shifts. As a result, approximately $30 \%$ of admissions had one or more shifts with only low RN staffing, $64 \%$ one or more shifts of only low nurse support staffing, $11 \%$ one or more shifts on which both RN and nursing support staffing was low and over half one or more high turnover shifts.

Following the approach used by two recent papers examining shortfalls in $\mathrm{RN}$ staffing against unit standards, ${ }^{90}$ we found in Models 1 and 2 that each shift of low RN staffing was associated with an increased hazard of mortality, a $2.3 \%$ increase in the hazard when the count of low RN shifts was extended over the whole admission and $9.1 \%$ when the count was restricted to the second to fifth days of the admission. 


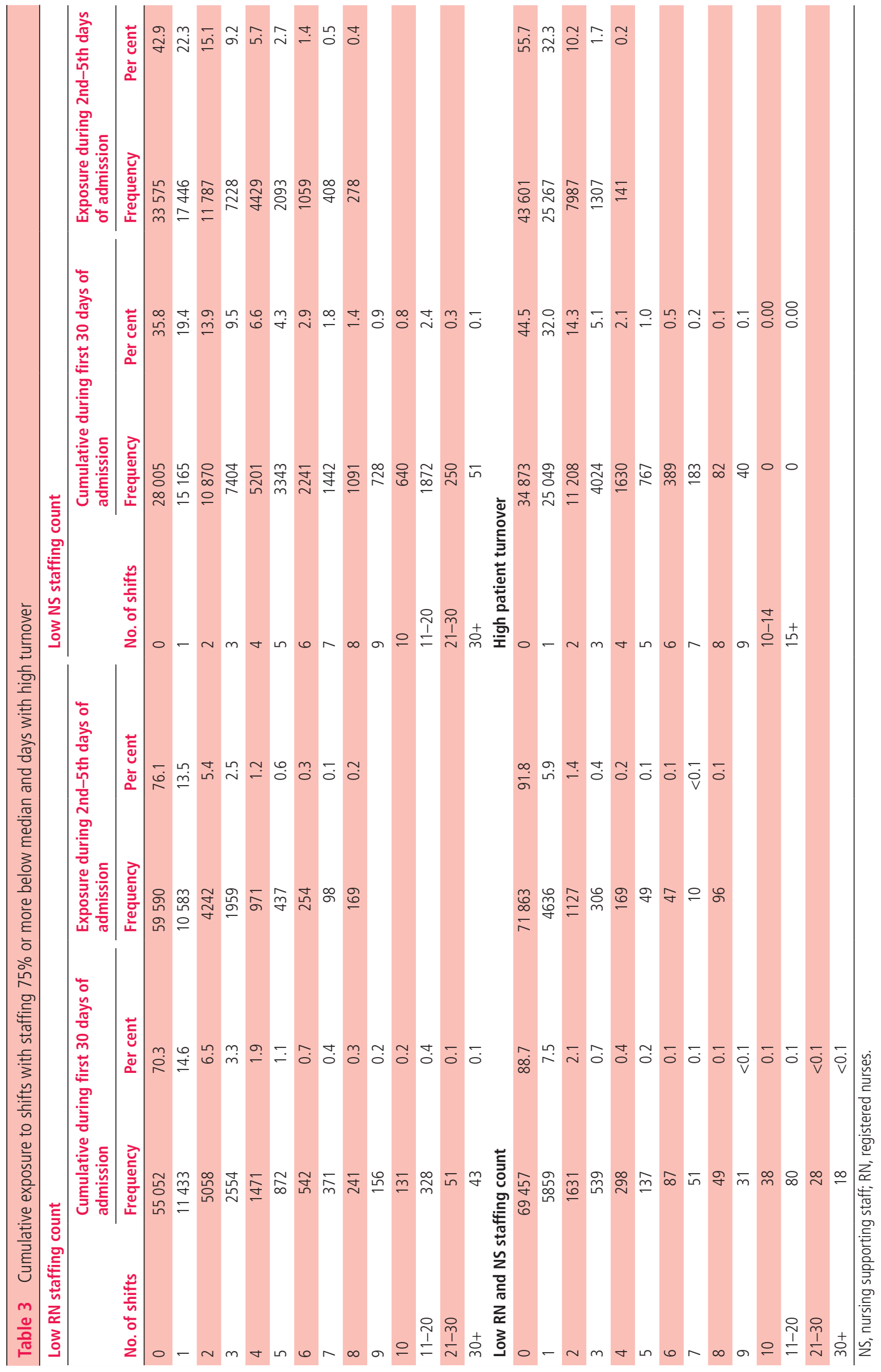

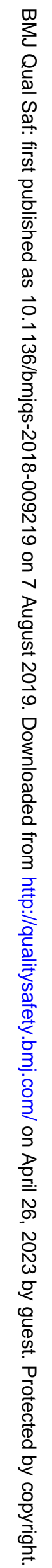


Table 4 Cox proportional hazard regression of mortality regressed on patient turnover on units, and measures of low registered nurse and nursing support staffing (78 303 patients, 133742 unique patient-unit-shift observations)

\begin{tabular}{|c|c|c|c|c|}
\hline \multirow[b]{2}{*}{ Variable } & \multirow[b]{2}{*}{$\mathrm{HR}$} & \multicolumn{2}{|c|}{$95 \% \mathrm{Cl}$} & \multirow[b]{2}{*}{$P$ value } \\
\hline & & Lower & Upper & \\
\hline & \multicolumn{4}{|c|}{ Model 1: Number of shifts patient experienced with low RN staffing or high turnover } \\
\hline Number of low RN shifts & 1.023 & 1.011 & 1.035 & $<0.001$ \\
\hline \multirow[t]{2}{*}{ Number of high turnover shifts } & 0.984 & 0.955 & 1.013 & 0.270 \\
\hline & \multicolumn{4}{|c|}{$\begin{array}{l}\text { Model 2: Number of shifts patient experienced with low registered nurse staffing or high turnover in } \\
\text { second to fifth days of admission }\end{array}$} \\
\hline Number of low RN shifts & 1.091 & 1.059 & 1.125 & $<0.001$ \\
\hline \multirow[t]{2}{*}{ Number of high turnover shifts } & 0.970 & 0.924 & 1.017 & 0.210 \\
\hline & \multicolumn{4}{|c|}{$\begin{array}{l}\text { Model 3: Number of shifts patient experienced with low registered nurse or nursing support staffing } \\
\text { or high turnover }\end{array}$} \\
\hline Number of low RN shifts & 1.027 & 1.002 & 1.053 & 0.035 \\
\hline Number of low nursing support shifts & 1.030 & 1.017 & 1.042 & $<0.001$ \\
\hline $\begin{array}{l}\text { Number of shifts with both low RN and nursing } \\
\text { support }\end{array}$ & 1.025 & 1.008 & 1.043 & 0.004 \\
\hline \multirow[t]{2}{*}{ Number of high turnover shifts } & 0.990 & 0.962 & 1.020 & 0.515 \\
\hline & \multicolumn{4}{|c|}{$\begin{array}{l}\text { Model 4: Number of shifts patient experienced with low registered nurse or nursing support staffing } \\
\text { or high turnover in second to fifth days of admission }\end{array}$} \\
\hline Number of low RN shifts & 1.048 & 0.998 & 1.100 & 0.061 \\
\hline Number of low nursing support-shifts & 1.032 & 1.008 & 1.057 & 0.010 \\
\hline $\begin{array}{l}\text { Number of shifts with both low RN and nursing } \\
\text { support }\end{array}$ & 1.136 & 1.089 & 1.185 & $<0.001$ \\
\hline Number of high turnover shifts & 0.976 & 0.93 & 1.024 & 0.314 \\
\hline
\end{tabular}

These results are consistent with those in the two previous papers. Unlike the results reported in the Needleman 2011 paper, ${ }^{9}$ we found no association of exposure to high patient turnover shifts and mortality.

We extended the prior research by examining the combined association of exposure to shifts with low $\mathrm{RN}$ staffing and low nursing support staffing. In both Models 3 and 4, we found an association with mortality of exposure to shifts with only low RN staffing, only low nursing support staffing and shifts where staffing of both RNs and nursing support staff was low. In Model 3, the estimates were comparable across low staffing shifts including where both $\mathrm{RN}$ and nursing support staff were low. In Model 4, the effects are larger than in the other models for low $\mathrm{RN}$ only staffing and the hazard substantially elevated for shifts with both low RN and nursing support staffing.

In a recent paper by Griffiths and colleagues, using a continuous measure of staffing below and above unit mean levels in a UK hospital, the researchers found both effects of low RN and low nursing support staffing on mortality. ${ }^{21}$ In that study, the authors did not find the interaction effect observed here as the elevated hazard observed in our Model 4.

This study and the Griffiths study examine nursing support staffing not as a substitute for RNs, as studies of skill mix do, but rather, they examine the impact of shortfalls in support staffing given established
$\mathrm{RN}$-nursing support staffing models. The findings of both of these studies raise questions regarding the basis of the association of nursing support staffing and mortality. We would propose two possible mechanisms that should be explored in further studies.

One is that nursing support staff, while not formally trained in patient assessment and monitoring, nonetheless contribute to these tasks as part of their contact with patients and through a developed ability to recognise patients who may need attention by others on the staff. When nursing support staff are less available, this contribution to the safety of patients is reduced.

A second possible mechanism involves a shift of the work of nursing support staff to RNs when nursing support staffing is low, reducing the RNs ability to carry out their other work, notably assessment and monitoring. This mechanism is suggested by the limited literature examining $\mathrm{RN}$ assumption of transferable work or work that is primarily the support staff's, such as delivering and retrieving food trays, transporting patients, obtaining supplies and equipment and arranging transportation, and the role of low support staffing in increasing the work load of RNs. ${ }^{22}$ The impact of assumption of these necessary tasks and potential crowd out of other RN work can be linked to the growing literature on the role of missed care by RNs when staffing is low as a contributor to increased adverse events such as mortality. ${ }^{23-29}$ 
Future research should examine the mechanisms by which low nursing support staffing increases patient risk, whether it reflects the direct loss of nursing support staff work or the increased demands on RNs, and whether the risk when both $\mathrm{RN}$ and nursing support staffing are low is elevated, as reflected in our Model 4, or not, as observed in the Griffith study and our Model 3.

There are several limitations to this study. The measure of low staffing was based on typical unit experience and was not adjusted for shift-to-shift variations in patient acuity. In addition, $75 \%$ of median as a standard for low staffing was not independently assessed. The hospitals studied did not have staffing systems that present recommended staffing levels, and we cannot assess the sufficiency of staffing at the median for the period studied. Since the period examined, the institutions studied have modified their staffing.

A second limitation is that the study was conducted in only three hospitals associated with a large US academic medical centre. While the results are comparable to two other single institution studies ${ }^{920}$ and a study on hospital-acquired infections, ${ }^{30}$ replication in other institutions and with a broader set of outcomes is critical.

It has been suggested that one possible explanation for the association of low staffing and mortality is that staffing is set lower if patients are admitted to the unit for palliative rather than curative care. While we do not believe this explains the unit-specific day-to-day variations in staffing, we cannot rule this explanation out from our data.

The findings confirm what is known from the literature, that low $\mathrm{RN}$ staffing increases the risk for patients, and it also expands that conclusion. Our finding that the risk is intensified when support staffing for nurses is low, and the effect may be intensified when both RN and nursing support staffing are low is a new finding. Whatever the staffing model at an institution, our results suggest that shortfalls from typical or targeted staffing in both $\mathrm{RN}$ and nursing support staffing can have negative consequences for patients. This study should encourage hospital administrators and managers to strive for both adequate $\mathrm{RN}$ and nursing support staffing every shift to assure delivery of safe and reliable care. It also suggests that maintaining and reviewing data not only on average staffing but the frequency with which target staffing is not met may improve patient safety.

Contributors All authors participated in the design and conduct of the research, writing and/or editing of the manuscript.

Funding The study was supported by National Institute of Nursing Research (NINR R01 NR010822).

Competing interests None declared.

Patient consent for publication Not required.

Provenance and peer review Not commissioned; externally peer reviewed.
ORCID iD

Jack Needleman http://orcid.org/0000-0002-2875-0589

\section{REFERENCES}

1 Aiken LH, Clarke SP, Sloane DM, et al. Hospital nurse staffing and patient mortality, nurse burnout, and job dissatisfaction. JAMA 2002;288:1987-93.

2 Aiken LH, Sloane DM, Bruyneel L, et al. Nurse staffing and education and hospital mortality in nine European countries: a retrospective observational study. The Lancet 2014;383:1824-30.

3 Cho S-H, Ketefian S, Barkauskas VH, et al. The effects of nurse staffing on adverse events, morbidity, mortality, and medical costs. Nurs Res 2003;52:71-9.

4 Griffiths P. Staffing levels and patient outcomes. Nurs Manage 2009;16:22-3.

5 Kane RL, Shamliyan TA, Mueller C, et al. The association of registered nurse staffing levels and patient outcomes: systematic review and meta-analysis. Med Care 2007;45:1195-204.

6 Liang Y-W, Chen W-Y, Lee J-L, et al. Nurse staffing, direct nursing care hours and patient mortality in Taiwan: the longitudinal analysis of hospital nurse staffing and patient outcome study. BMC Health Serv Res 2012;12:44.

7 Needleman J, Buerhaus P, Mattke S, et al. Nurse-staffing levels and the quality of care in hospitals. N Engl J Med 2002;346:1715-22.

8 Needleman J. Nurse staffing: the knowns and unknowns. Nurs Econ 2015;33:5-7.

9 Needleman J, Buerhaus P, Pankratz VS, et al. Nurse staffing and inpatient hospital mortality. N Engl J Med 2011;364:1037-45.

10 Shekelle PG. Nurse-patient ratios as a patient safety strategy: a systematic review. Ann Intern Med 2013;158:404-9.

11 Tourangeau AE, Doran DM, McGillis Hall L, et al. Impact of hospital nursing care on 30-day mortality for acute medical patients. J Adv Nurs 2007;57:32-44.

12 Twigg DE, Gelder L, Myers H. The impact of understaffed shifts on nurse-sensitive outcomes. J Adv Nurs 2015.

13 Zhu X-wen, You L-ming, Zheng J, et al. Nurse staffing levels make a difference on patient outcomes: a multisite study in Chinese hospitals. J Nurs Scholarsh 2012;44:266-73.

14 Aiken LH, Sloane D, Griffiths P, et al. Nursing skill mix in European hospitals: cross-sectional study of the association with mortality, patient ratings, and quality of care. BMJ Qual Saf 2017;26:559-68.

15 Blegen MA, Goode CJ, Spetz J, et al. Nurse staffing effects on patient outcomes: safety-net and non-safety-net hospitals. Med Care 2011;49:406-14.

16 Estabrooks CA, Midodzi WK, Cummings GG, et al. The impact of hospital nursing characteristics on 30-day mortality. Nurs Res 2005;54:74???84-84.

17 Unruh L. Licensed nurse staffing and adverse events in hospitals. Med Care 2003;41:142-52.

18 Deyo R, Cherkin DC, Ciol MA. Adapting a clinical comorbidity index for use with ICD-9-CM administrative databases. J Clin Epidemiol 1992;45:613-9.

19 Liu J, Larson E, Hessels A, et al. Comparison of measures to predict mortality and length of stay in hospitalized patients. Nurs Res 2019;68:200-9.

20 Fagerström L, Kinnunen M, Saarela J. Nursing workload, patient safety incidents and mortality: an observational study from Finland. BMJ Open 2018;8:e016367. 


\section{Original research}

21 Griffiths P, Maruotti A, Recio Saucedo A, et al. Nurse staffing, nursing assistants and hospital mortality: retrospective longitudinal cohort study. BMJ Qual Saf 2019;28:609-17.

22 Ball JE, Griffiths P, Rafferty AM, et al. A cross-sectional study of 'care left undone' on nursing shifts in hospitals. J Adv Nurs 2016;72:2086-97.

23 Ball JE, Murrells T, Rafferty AM, et al. 'Care left undone' during nursing shifts: associations with workload and perceived quality of care. BMJ Qual Saf 2014;23:116-25.

24 Bruyneel L, Li B, Ausserhofer D, et al. Organization of hospital nursing, provision of nursing care, and patient experiences with care in Europe. Med Care Res Rev 2015;72:643-64.

25 Griffiths P, Recio-Saucedo A, Dall'Ora C, et al. The association between nurse staffing and omissions in nursing care: a systematic review. J Adv Nurs 2018;74:1474-87.
26 Griffiths P, Ball J, Bloor K, et al. Health services and delivery research. nurse staffing levels, missed vital signs and mortality in hospitals: retrospective longitudinal observational study. Southampton UK: NIHR Journals Library, 2018.

27 Kalisch BJ, Tschannen D, Lee KH, et al. Staffing, and patient falls. Journal of Nursing Care Quality 2012;27:6-12.

28 Kalisch BJ, Xie B, Dabney BW. Patient-Reported missed nursing care correlated with adverse events. Am J Med Qual 2014;29:415-22.

29 Schubert M, Clarke SP, Aiken LH, et al. Associations between rationing of nursing care and inpatient mortality in Swiss hospitals. Int J Qual Health Care 2012;24:230-8.

30 Shang J, Needleman J, Liu J, et al. Nurse staffing and healthcare-associated infection, Unit-Level analysis. JONA: The Journal of Nursing Administration 2019;49:260-5. 